\title{
MicroRNA and messenger RNA As Potential Urinary Biomarkers in Prostate Cancer
}

\begin{abstract}
Keywords: Prostate cancer; Biomarker; miR-21-5p; PDCD-4
Abstract

Introduction: Prostate Cancer (PCa) is the fifth leading cause of death world wide and these condmost common

cancerinmen. Studies to search for new biomarkers, especially with non-invasivemethods, are carried out, one of which is urinary biomarker as an early detection and predictors of PC aprognosis. microRNA (miRNA) and messenger RNA(mRNA) has proven to have important roles in various oncogenic processes.

Material and methods: Urine samples collected from 145 patients were examined, 45 patients diagnosed with Benign Prostate Hyperplasia (BPH) and 100 patients diagnosed with PCa.Urine samples were collected from each patient and examined in the biomolecular laboratory. The geneexpression were analyze dusing qPCR analysis using the qPCRCFX 96 thermocycler (Bio-Rad).

Results: The expression of miR-21-5p was higher in BPH group compared to PC a groups, both non- metastatic and metastatic, with $\mathrm{p}$-values of 0.004 and 0.017 , respectively. BPH showed the highest mRNA expression of PDCD-4.

Conclusion: The overexpression of miR-21-5p shown in this study could be a potential non-invasive diagnostic tool for patients with $\mathrm{PCa}$. The lower expression mRNA of PDCD-4 in non-metastatic compared to metastatic PCa group could be potential prognostic biomarker in PCa.
\end{abstract}

\section{Introduction}

Prostate Cancer (PCa) isthe fifth leading cause of death worldwide and the second most common cancer in men. Worldwide, it was estimated that around 1,276,106 newly diagnosed PCa were reported in 2018 [1]. The diagnosis of suspected PCa is made when the abnormality from the Digital Rectal Examination (DRE) and elevated Prostate Specific Antigen (PSA) present [2]. PSA value of morethan $4 \mathrm{ng} / \mathrm{mlisan}$ indication for prostate biopsy examination and this border line value hasa positive predictive value of only $37 \%$, and a negative predictive value of $91 \%$ [2]. Therefore, rigorous studies searching for new biomarkers with non-invasive methods that have higher specificity than PSA and can be used as an early detectors as well as prognostic predictors of PCa, have emerged [3].

microRNA (miRNA)is a non-coding RNA molecule which regulates gene expression and influences both the stability and the efficiency of target messenger RNA (mRNA) [4]. It has been proventhat specific miRNA plays a key role in various oncogenic processes, including angiogenesis, epithelial-mesenchymal transition, and metastasis. Micro-RNA was suggested to be a potential biomarker in both serum and urine samples of patients with $\mathrm{PCa}$ [3]

miRNA-21 (miR-21) is a specific miRNA which is frequently up-regulated in cancer and has many targets of tumor suppressors, such as Phosphatase And Tensin Homolog (PTEN), Programmed Cell Death 4 (PDCD4), Tropomyosin1 (alpha) (TPM1),
Journal of

\section{Urology \& Nephrology}

\author{
Danarto $\mathbf{R}^{1}$, Astuti $\mathbf{I}^{2}$, Umbas $\mathbf{R}^{3}$, and Mubarika \\ Haryana $\mathbf{S}^{4^{*}}$
}

${ }^{1}$ Department of Surgery, Universitas Gadjah Mada, Indonesia

${ }^{2}$ Department of Pharmacology, Universitas GadjahMada, Indonesia

${ }^{3}$ Departmentof Urology, Universitas Indonesia, Indonesia

${ }^{4}$ Postgraduate Doctoral Program, UniversitasGadjahMada, Indonesia

\section{Address for Correspondence}

Mubarika Haryana S, Postgraduate Doctoral Program, Faculty of Medicine, Universitas Gadjah Mada, Yogyakarta, Indonesia 55281, Indonesia; E-mail : Sofia.mubarika@gmail.com

Submission: 11 July, 2020

Accepted: 5 October, 2020

Published: 9 October, 2020

Copyright: (c) 2020 Danarto R, et al. This is an open access article distributed under the Creative Commons Attribution License, which permits unrestricted use, distribution, and reproduction in any medium, provided the original work is properly cited.

Mammary Serine Protease Inhibitor (SERPINB5), and ReversionInducing-Cysteine-Richprotein with Kazal motifs (RECK). It had been shown that miR-21 has a crucial role in disrupting growth by inducing apoptosis. miR-21 had used to know the profile CP/CPPS and clear cell renal cell carcinoma therefore miRNA-21 also used as a potential marker to know PCa [5,6]. Programmed Cell Death 4 (PDCD-4) is known as a tumor suppressor gene. PDCD-4 decreased in common tumor entities. The Reduction of PDCD-4 expressions potential urinary biomarkers in PCa Programmed Cell Death 4 (PDCD-4) is a tumors uppers orgene that has been decreased in Regulation formany tumor entities. Increased regulation of PDCD4 can be found after th einitiation of apoptosis, contrary to the reduction of PDCD-4expression can contribute tothe anti-apoptotic nature of cancercells [7]. We aimed to investigate miR-21 and PDCD4, expression as potential urinary biomarkers in PCa.

\section{Material and Methods}

\section{Sample collection and exosome isolation}

Urine samples collected from 145 patients were examined, 45 patients diagnosed with Benign Prostate Hyperplasia (BPH), and 100 patients diagnosed with PCa. All of the patients participated in this study signed written consent.This study received ethical approval from the Institutional Review Board of Universitas Gadjah Mada (approval number: KE/FK/0449/EC/2019). We collected $15 \mathrm{ml}$ of urine from each patient. The samples were then distributed into fourvials $(1.5 \mathrm{~mL})$, and each vial contained $1 \mathrm{~mL}$ of the urine sample. After the centrifugation, the supernatant was extracted and filled into new a vialandkeptina refrigerator at $-80^{\circ} \mathrm{C}$. The exosomes isolation was conducted using the miRCURY exosome isolationkit (Exiqon, Denmark), by adding $400 \mathrm{uL}$ precipitation buffer B into the vial, and the mixture was then incubated inarefrigerator at $4^{\circ} \mathrm{C}$ for 60 minutes.

\section{RNA isolation and cDNA synthesis}

The total RNA was extracted using a miRCURYRNA Isolation 


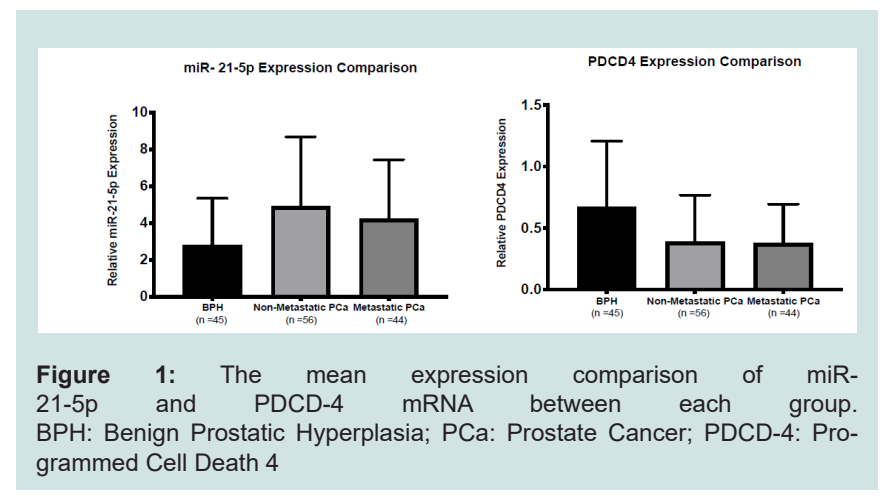

Table 1: Sequence table.

\begin{tabular}{|c|c|}
\hline \multirow{2}{*}{ hsa-miR-21-5p } & Sequence \\
\hline \multirow{2}{*}{ PDCD-4 } & Forward: 5' TGT GCT GGA GCG GTT TGT AG 3' \\
\cline { 2 - 2 } & Reverse: 5' CAA AAC GCT TTC TGC CCC TTG 3' \\
\hline
\end{tabular}

Kit-Biofluid kit (Exiqon, Denmark). Complementary DNA (cDNA) was synthesized usinga Universal cDNA Synthesiskit (Exiqon, Denmark).

\section{Quantitative polymerase chain reaction (qPCR) and data analysis}

Quantitative PCR was conducted using an ExiLent SYBR Green Master Mixkit (Exiqon, Denmark), primersset (forward and reverse), and diluted cDNA. The qPCR analysis of gene expression was performed using the qPCRCFX96 thermocycler (Bio-Rad). All of the procedures followed the manufacturer's recommendations, and statistical analyses were performed using the SPSS Version 23 and Graph Pad Prism 7. In this study, statistical significance was setata p-value $<0.05$ (Table 1 and 2).

Mean age of the samples by $\mathrm{BPH}$, non-metastatic $\mathrm{PCa}$ and metastatic PCa were older than 65 years old. Characteristic median PSA were appropriate as predisposition lower in $\mathrm{BPH}$ rather than PCa.

The median age of the samples were 65(46-88), 69.5(52-84) and 67(49-82) for $\mathrm{BPH}$, non-metastatic PCa, and metastatic PCa, respectively. The median PSA score for $\mathrm{BPH}$, non- metastatic PCa, and metastatic PCa were 3.8(0.4-20.82), 37.3(2.51-386) and 107.2(23.16-1155) (Table 3,4 and Figure 1).

The expressions of each biomarker were analyzed using Mann Whitney Test. We found a significant difference between miR21-5p expression in the BPH group and $\mathrm{PCa}$, both metastatic and non-metastatic, withp-values of 0.017 and 0.004 , respectively. Never theless, expression of miR-21-5p between metastatic and nonmetastasic PCa showed in significant results. BPH group showed the highest expression of PDCD-4 mRNA. Significant difference was found between BPH group and PCa group, both metastatic and nonmetastatic.

In this study, miR-21-5p showed potential diagnostic value todetect PCa. The expression of miR-21-5p, using 1.34 as cut-off point had $83 \%$ sensitivity and $44.4 \%$ specificity.

\section{Discussion}

Upregulation of urine-based miR-21-5p was significantly higher in patients with $\mathrm{PCa}$ than patient with $\mathrm{BPH}$. This study indicated that the overexpression of urine-based miR-21-5p could be apotential non-invasive biomarker for diagnostic aspects of PCa which was aligned with our previous study [8]. This result was supported by previous studies which stated that the overexpression of miR-21in urine and serum samples of PCa patients played an essensial role as a diagnostic and prognostic biomarker [9-13]. PCa proliferation and invasion were significantly decreased by the inhibition of miR-21-5p [14]. Studies conducted by Li T. et al. and Ghorbanmehr, et al. showed increased miR-21-5p expression in urine sample from PCa patients $[15,16]$. As one of the best studied miRNAs, miR-21-5p demonstrated its oncogenic activity in most cancers [17]. Additionally, several previous studies suggested that oncomiR miR-21 had been involved in many solid and haematological organ malignancies [18-23]. It has been reported that miR-21-5p was expressed higher in PCa tissue than in normal prostate tissue [24,25]. Melbo-Jorgensen C. et al. showed overexpression of 21-5p in prostate cancer patients undergoing radical prostatectomy [26]. Further more, miR-21-5p, which was shown to contribute to prostate cell transformation and had been associated with cancer initiation, progression, and metastasis [2729], correlated with stronger PCa cell growth both in vitro and in vivo [30]. In addition, it provided resistance to docetaxelin PC-3 cells, although, knockdown of miR-21 in human cell was sensitive to docetaxel-induced apoptosis [31]. Same study by Kopczynska miRNA had a role in the resistance of prostate cancer with docetaxel and paclitaxel [32]. Study conducted by Porzycki et al. which showed the potential role of miR-21 as a potential diagnostic biomarker, had an analysis done using the ROC curve with the results of the area under the curve of 0.856 [10]. This findings was aligned with the study conducted by Stuopelyte et al. whose area under the curve value was 0.633. The urine specificity of miR-21 was higher than that of PSA (76.22\% vs $63.57 \%$ ) but the sensitivity value was almost the same as PSA (47.83\% vs $52.38 \%$ )(33).Our study showed the similar result, where the value of the area under the curve on the ROC miR-21-5p curve is 0.658 . Compared with the previous studies, the sensitivity of miR-21-5p in this study was found to be higher (79\%) while the specificity was lower (44.4\%).

In this study we found that the expression of PDCD-4mRNA was lower in $\mathrm{PC}$ ag roup than in $\mathrm{BPH}$ group. Lowe rexpression was found in metastatic group compared to non-metastatic group. This study indicated that lower expression of urine-based PDCD-4 could be a potential non-invasive biomarker for prognostic aspectsof PCa. Several studies showed that the PDCD-4 mRNA was expressed lower in the PCa group compared to BPH. Lower expression was also found inmetastatic group compared to the non-metastatic group. Consistent with previous studies, a significant difference in the PDCD-4 expression was found between PCa and prostatichy perplasia [34]. Down regulation of the PDCD-4 gene in prostate cancer tissue was also found in a study by Fischer N. et al. In PDCD4 nuclear and cytoplasmic staining, there was a significant decrease in prostate cancer tissue [25]. Reduced PDCD-4 expression was associated with PCa progression and pathologic features $[21,35,36]$. Studies conducted in mices, proved that PDCD-4 was a true tumor suppressor [37,38]. A recent study by Aameri, observed localization od PDCD-4 mainly in nuclei epithelial cells in normal but not in prostate cancer specimens [35]. Another study by Zennami, PDCD-4 
Citation: Danarto R, Astuti I, Umbas R, Mubarika Haryana S. MicroRNA and messenger RNA As Potential Urinary Biomarkers in Prostate Cancer. J Urol Nephrol. 2020;7(1): 4.

ISSN: $2380-0585$

Table 2: Demographic characteristics of recruited participants.

\begin{tabular}{|c|c|c|}
\hline & BPH & Non-Metastatic PCa \\
\hline Subject & 45 & 56 \\
\hline Age (minimum-maximum, median) [years] & $46-88,65$ & 44 \\
\hline Age (minimum-maximum, median) $[\mathrm{ng} / \mathrm{mL}]$ & $0.4-20.82,3.8$ & $49-82,67$ \\
\hline
\end{tabular}

BPH: Benign Prostatic Hyperplasia; PCa: Prostate Cancer; PSA: Prostate Specific Antigen.

Table 3: P-Value of mann whitney test for each biomarker.

\begin{tabular}{|c|c|c|}
\hline Groups & & miR-21-5p \\
\hline BPH & Non Metastatic PCa & 0.004 \\
\hline BPH & Metastatic PCa & 0.005 \\
\hline Metastatic PCa & Non Metastatic PCa & 0.017 \\
\hline BPH & PCa & 0.015 \\
\hline
\end{tabular}

BPH: Benign Prostatic Hyperplasia; PCa: Prostate Cancer; PDCD-4: Programmed Cell Death 4.

Table 4. Biomarker expression on urine.

\begin{tabular}{|c|c|c|c|}
\hline Variable & \multicolumn{2}{|c|}{ Mean \pm SD } \\
\hline miR-21-5p & BPH & Non-metastatic \\
\hline miR-200c-3p & $2.78 \pm 2.25$ & $4.9 \pm 3.77$ & Metastatic \\
\hline PCDCD4 & $1.94 \pm 1.84$ & $0.85 \pm 0.70$ & $4.2 \pm 3.21$ \\
\hline E-Cadherin & $0.67 \pm 0.53$ & $0.39 \pm 0.37$ & $0.3 \pm \pm 1.07$ \\
\hline
\end{tabular}

mRNA and protein level was significantly decreased in higher Gleason score tumor using 546 patient samples [39]. In a study conducted by Zennami et al. demonstrated that PDCD4 regulates proliferation, apoptosis and castration resistance in prostate cancer [40] Matsuhashi et al. found that PDCD-4 protein synthesis was inhibited by miR-21 in prostate cancer. Dong et al. also found that PDCD-4 mRNA expression was decreased in prostate cancer compared to IL6-inhibited BPH. In this study, it is known that PDCD4 expression in urine can be a diagnostic tool for prostate cancer with a sensitivity value of $90 \%$, but with a specificity of $42.2 \%$. Translation of tumor suppressor gene PDCD-4 is negatively regulated by miR-21(34) [41] As the target of miR-21 regulationin PC a cells, PDCD-4 expression will bereduced by miR-21, and lower PDCD-4 expression correlates with tumor cell invasion and distant metastasis in PCa. Other studies showed and rogen stimulation in PCa cellline associated with lower PDCD- 4 protein expression, and contribute to miR-21 induced cell growth and castration resistance in $\mathrm{PCa}$ [40].

\section{Conclusion}

The overexpression of miR-21-5p shown in this study could be a potential non-invasive diagnostic tool for patients with PCa. The lower mRNA expression of PDCD-4 in non-metastatic compared to metastatic PCa group could be potential prognostic biomarker in PCa. Further studies with alarger population are required to investigate the role of miR-21-5p and PDCD-4as biomarkers in PCa. The combination of both durinary based miRNA and mRNA could give potential contribution in management of $\mathrm{PCa}$.

\section{References}

1. Bray F, Ferlay J, Soerjomataram I, Siegel RL, Torre LA, et al. (2018) Global cancer statistics 2018: GLOBOCAN estimates of incidence and mortality worldwide for 36 cancers in 185 countries. CA Cancer J Clin 394-424.

2. Nogueira L, Corradi R, Eastham JA (2009) Prostatic specific antigen for Prostate Cancer detection. Int Braz J Urol 35: 521-529.

3. Cui M, Wang H, Yao X, Zhang D, Xie Y, et al. (2019) Circulating MicroRNAs in Cancer: Potential and Challenge. Front Genet 10.
4. Folini M, Gandellini P, Longoni N, Profumo V, Callari M, et al. (2010) miR-21: An oncomir on strike in prostate cancer. Mol Cancer 9: 12.

5. Chen Y, Chen SN, Zhang J, Wang YM, Jia Z, et al. (2018) Expression profile of microRNAs in expressed prostatic secretion of healthy men and patients with IIIA chronic prostatitis/chronic pelvic pain syndrome. Oncotarget 9: 12186-12200.

6. Petrozza V, Pastore AL, Palleschi G, Tito C, Porta N, et al. (2017) Secreted miR-210-3p as non-invasive biomarker in clear cell renal cell carcinoma. Oncotarget 8: 69551-69558.

7. Li JZH, Gao W, Ho WK, Lei W Bin, Wei WI, et al. (2016) The clinical association of programmed cell death protein 4 (PDCD4) with solid tumors and its prognostic significance: a meta-analysis. Chin J Cancer 35: 95.

8. Danarto R, Astuti I, Umbas R, Haryana SM (2020) Urine miR-21-5p and miR-200c-3p as potential non-invasive biomarkers in patients with prostate cancer. Turkish J Urol 46: 26-30.

9. Endzelinš E, Berger A, Melne V, Bajo-Santos C, Sobolevska K, et al. (2017) Detection of circulating miRNAs: Comparative analysis of extracellular vesicle-incorporated miRNAs and cell-free miRNAs in whole plasma of prostate cancer patients. BMC Cancer 17: 1-13.

10. Porzycki P, Ciszkowicz E, Semik M, Tyrka M (2018) Combination of three miRNA (miR-141, miR-21, and miR-375) as potential diagnostic tool for prostate cancer recognition. Int Urol Nephrol 1619-1626.

11. Koppers-lalic D, Hackenberg M, Menezes R De, Misovic B, Wachalska M (2016) Non-invasive prostate cancer detection by measuring miRNA variants (isomiRs ) in urine extracellular vesicles 7: 2256-22578.

12. Samsonov R, Shtam T, Burdakov V, Glotov A, Tsyrlina E, et al (2016) Lectininduced agglutination method of urinary exosomes isolation followed by miRNA analysis: Application for prostate cancer diagnostic. Prostate 76: 68-79.

13. Feng YH, Wu CL, Shiau AL, Lee JC, Chang JG, Lu PJ, et al. (2012) MicroRNA-21-mediated regulation of Sprouty2 protein expression enhances the cytotoxic effect of 5-fluorouracil and metformin in colon cancer cells. Int $\mathrm{J}$ Mol Med 29: 920-926

14. Báez-Vega PM, Vargas IME, Valiyeva F, Rosado JE, Roman A, et al. (2016) Targeting miR-21-3p inhibits proliferation and invasion of ovarian cancer cells. Oncotarget 7: 36321-36337.

15. Li T, Li R, Li Y, Zhong S, Chen Y, et al. (2012) miR-21 as an Independent Biochemical Recurrence Predictor and Potential Therapeutic Target for Prostate Cancer. J urol 187: 1466-1472. 
Citation: Danarto R, Astuti I, Umbas R, Mubarika Haryana S. MicroRNA and messenger RNA As Potential Urinary Biomarkers in Prostate Cancer. J Urol Nephrol. 2020;7(1): 4.

\section{ISSN: 2380-0585}

16. Ghorbanmehr N, Gharbi S, Korsching E, Tavallaei M, Einollahi B (2019) miR21-5p, miR-141-3p, and miR-205-5p levels in urine-promising biomarkers for the identification of prostate and bladder cancer. Prostate. 79: 88-95.

17. Selcuklu SD, Donoghue MTA, Spillane C (2009) miR-21 as a key regulator of oncogenic processes 37: 918-925.

18. Liu LZ, Li C, Chen Q, Jing Y, Carpenter R, et al. (2011) Mir-21 induced angiogenesis through AKT and ERK activation and HIF-1 $\alpha$ expression. PLoS One 2-10.

19. Erbes T, Hirschfeld M, Rücker G, Jaeger M, Boas J, et al. (2015) Feasibility of urinary microRNA detection in breast cancer patients and its potential as an innovative non-invasive biomarker. BMC Cancer 15: 1-9.

20. Li S, Yang X, Yang J, Zhen J, Zhang D (2016) Serum microRNA-21 as potential diagnostic biomarker for breast cancer: a systematic review and meta-analysis. Clin Exp Med 16: 29-35.

21. Asangani IA, Rasheed SAK, Nikolova DA, Leupold JH, Colburn NH, et al (2008) MicroRNA-21 (miR-21) post-transcriptionally downregulates tumo suppressor Pdcd4 and stimulates invasion, intravasation and metastasis in colorectal cancer. Oncogene 27: 2128-2136.

22. Yu Y, Nangia-Makker P, Farhana L, Rajendra SG, Levi E (2015) miR-21 and miR-145 cooperation in regulation of colon cancer stem cells. Mol Cance 14: 98

23. Hatley ME, Patrick DM, Garcia MR, Richardson JA, et al. (2010) Modulation of K-Ras-dependent lung tumorigenesis by MicroRNA-21. Cancer Cell 18 : 282-293

24. Amankwah EK, Anegbe E, Park H, Pow-Sang J, Hakam A, et al. (2013) MiR21 , miR-221 and miR-222 expression and prostate cancer recurrence among obese and non-obese cases. Asian J Androl 15: 226-230.

25. Lewis BP, Shih I, Jones-rhoades MW, Bartel DP, Burge CB (2003) Prediction of Mammalian MicroRNA Targets 115: 787-798.

26. Zhang B, Pan X, Cobb GP, Anderson TA (2007) microRNAs as oncogenes and tumor suppressors. Dev Biol 302: 1-12.

27. Reis ST, Pontes-Junior J, Antunes AA, Dall'Oglio MF, Dip N, et al. (2012) MiR21 may acts as an oncomir by targeting RECK, a matrix metalloproteinase regulator, in prostate cancer. BMC Urol 12.

28. Coppola V, Musumeci M, Patrizii M, Cannistraci A, Addario A, et al. (2013) BTG2 loss and miR-21 upregulation contribute to prostate cell transformation by inducing luminal markers expression and epithelial-mesenchymal transition. Oncogene 32: 1843-1853.
29. Iorio MV, Croce CM (2012) MicroRNA dysregulation in cancer: Diagnostics, monitoring and therapeutics. A comprehensive review. EMBO Mol Med 4:143-159.

30. Ribas J, Ni X, Haffner M, Wentzel EA, Hassanzadeh A, et al. (2010) Growth 69: 7165-7169.

31. Shi GH, Ye DW, Yao XD, Zhang SL, Dai B, et al. (2010) Involvement of microRNA-21 in mediating chemo-resistance to docetaxel in androgenindependent prostate cancer PC3 cells. Acta Pharmacol Sin 31: 867-873.

32. Kopczyńska E (2015) Role of microRNAs in the resistance of prostate cancer to docetaxel and paclitaxel. Wspolczesna Onkol 19: 423-427.

33. Stuopelyt K, Dani K, Jankevi F, Jarmalait S (2016) ScienceDirect Detection of miRNAs in urine of prostate cancer patients 2: 116-124.

34. Dong B, Shi Z, Wang J, Wu J, Yang Z, et al. (2015) IL-6 inhibits the targeted modulation of PDCD4 by miR-21 in prostate cancer. PLoS One10: 1-10.

35. Al Aameri RFH, Sheth S, Alanisi EMA, Borse V, Mukherje D, et al. (2017) Tonic suppression of PCAT29 by the IL- 6 signaling pathway in prostate cancer: Reversal by resveratrol. PLoS One 12: 1-17.

36. Li CR, Su JJM, Wang WY, Lee MTL, Wang TY, et al. (2013) Molecular profiling of prostatic acinar morphogenesis identifies PDCD4 and KLF6 as tissue architecture-specific prognostic markers in prostate cancer. Am J Pathol 182: 363-374.

37. Hilliard A, Hilliard B, Zheng SJ, Sun H, Miwa T, et al. (2006) Translationa Regulation of Autoimmune Inflammation and Lymphoma Genesis by Programmed Cell Death 4. J Immuno 177: 8095-8102.

38. Jansen AP, Zennami K, Choi SM, Liao R, Li Y, et al. (2012) HHS Public Access 17: 618-627.

39. Camalier CE, Colburn NH (2005) Epidermal expression of the translation inhibitor programmed cell death 4 suppresses tumorigenesis. Cancer Res 65: 6034-6041.

40. Zennami K, Hatano K, Liao R, Rafiqi F, Choi SM, et al. (2017) Mp99-14 Pdcd4 Is a Check Point of Mir-21 Induced Castration Resistance in Human Prostate Cancer. J Urol 197: 1325-1326.

41. Lu Z, Liu M, Stribinskis V, Klinge CM, Ramos KS, et al. (2008) MicroRNA-21 promotes cell transformation by targeting the programmed cell death 4 gene. Oncogene 27: 4373-4379. 